\title{
Contributions of longitudinal track unevenness and track stiffness variation to railway induced vibration
}

\author{
M. Germonpréa,*, J.C.O. Nielsen ${ }^{\mathrm{b}}$, G. Degrande ${ }^{\mathrm{a}}$, G. Lombaert ${ }^{\mathrm{a}}$ \\ ${ }^{a}$ KU Leuven, Department of Civil Engineering, Kasteelpark Arenberg 40, 3001 Leuven, Belgium \\ ${ }^{b}$ Chalmers University of Technology, Department of Mechanics and Maritime Sciences, SE-412 96 Gothenburg, Sweden
}

\begin{abstract}
Dynamic train-track interaction originates from excitation mechanisms such as longitudinal track unevenness, parametric excitation due to track stiffness variation and impact excitation due to wheel flats, wheel out-of-roundness and rail joints. Track stiffness variation can be regarded as longitudinal track unevenness in loaded condition, but for the mitigation of track geometry degradation it is important to distinguish between track unevenness in unloaded condition and track stiffness variation. This paper studies how longitudinal track unevenness and track stiffness variation contribute to railway induced vibration. A case study is performed for a railway line in Furet, Sweden. Based on measured track unevenness and stiffness data from the IMV 100 track recording car, the train-track interaction forces and free field vibrations are computed for each of these two excitation mechanisms separately, as well as for a combination of both. The computed free field vibrations are in good agreement with measured vibrations at the same site. The contribution of the track stiffness variation to the interaction forces and free field vibrations is much lower than the contribution of the longitudinal track unevenness. Track stiffness variation can also be modeled as equivalent track unevenness, leading to results slightly different from those obtained when track unevenness and track stiffness variation are modeled separately, and a poorer agreement with the measured vibrations.
\end{abstract} Keywords: Track modeling, track unevenness, parametric excitation, train-track interaction, railway induced vibration

\section{Introduction}

Ground-borne noise and vibration due to railway traffic are generated by a combination of quasi-static and dynamic excitation. The quasi-static component results from the moving train loads while the dynamic component is due to train-track interaction caused by longitudinal track unevenness, parametric excitation due to track stiffness variation (transition zones, hanging sleepers, variation in track and subgrade stiffness) and impact excitation due to wheel flats, wheel out-of-roundness, switches, crossings and rail joints [1-4].

\footnotetext{
*Corresponding author. Tel.: +32 (0) 16320421.

Email address: matthias.germonpre@kuleuven.be (M. Germonpré)

Postprint submitted to Journal of Sound and Vibration

Published version: M. Germonpré, J.C.O. Nielsen, G. Degrande and G. Lombaert. Contributions of longitudinal track unevenness and track stiffness variation to railway induced vibration. Journal of Sound and Vibration, 437:292-307, 2018. https://doi.org/10.1016/j.jsv.2018.08.060
} 
Track stiffness variation can be regarded as longitudinal track unevenness in loaded condition; it is important, however, to distinguish between track unevenness in unloaded condition and track stiffness variation in order to understand track geometry degradation phenomena $[5,6]$. Large track stiffness variation leads to high dynamic train-track interaction forces that may induce local track settlements. The resulting differential track settlements lead to track geometry irregularities, causing higher train-track interaction forces and the further development of track settlement [7].

Track stiffness can be investigated using standstill or rolling measurements, the former being far more time consuming and expensive since the track is not available for normal railway operation. Several rolling track stiffness measurement methods have been developed in the last two decades in Switzerland (SBB Track deflection measurement wagon), Sweden (Rolling Stiffness Measurement Vehicle-RSMV [8] and Infranord Measurement Vehicle-IMV [9]), USA (M-rail [10]) and China (CARS [11]). These methods differ in static preload, excitation frequency, vehicle speed and spatial resolution. Therefore, the measured track stiffness will in general depend on the applied measurement method.

Andersen and Nielsen [12] considered the effect of track stiffness variation on railway induced vibration, simulating the passage of a single-degree-of-freedom train model on an infinite Euler-Bernoulli beam resting on a Kelvin foundation with varying stiffness. The variation of the foundation stiffness was modeled as a stochastic homogeneous field consisting of a small random variation around a deterministic mean value. Oscarsson [13] followed a similar approach, taking into account variations in rail pad stiffness, ballast stiffness and dynamic ballast-subgrade mass based on field and laboratory measurements. Stochastic realizations of the stiffness variation of the different components were generated by means of the Latin Hypercube sampling method with correlation control. Rhayma et al. [14] modeled the track as rails and sleepers supported by four layers representing ballast, subballast, form layer and natural ground and considered a spatial variation of the thickness and Young's modulus of these layers. Li and Berggren [15] used stiffness measurement data of the RSMV from a railway line in Sweden to compute the effect of track stiffness variation on the train-track interaction force, rail deflection and wheel acceleration.

The aim of this paper is to investigate the contribution of longitudinal track unevenness and track stiffness variation to the train-track interaction forces and free field vibrations. In addition, it is studied how track stiffness variation can be modeled as equivalent track unevenness to reduce the modeling effort while only introducing small modeling errors. Measurements of the IMV100 track recording vehicle on the railway line in Furet (Sweden) are used as input data. In Section 2, the site in Furet is described. Section 3 discusses the measured track unevenness and track stiffness variation at this site. In Section 4, the track models used for the computation of the interaction forces and free field vibrations are introduced. In Section 5, the interaction forces due to longitudinal track unevenness and track stiffness variation are computed for the passage of a passenger train. Next, the free field vibrations caused by both excitation mechanisms are calculated and compared to measured vibration levels. In Section 6, track stiffness variation is modeled 
alternatively by considering an equivalent track unevenness. The results of this approach are compared to those obtained by a more detailed representation of the stiffness variation. Section 7 contains the conclusions of this paper.

\section{Site in Furet}

The railway line in Furet (Sweden) is used to investigate the individual contributions of longitudinal track unevenness and track stiffness variation to the dynamic train-track interaction. This site is located in the southwest of Sweden along Västkustbanan (the West Coast Line) between Gothenburg and Malmö and consists of two ballasted tracks at grade.

Following complaints by local residents regarding excessive railway induced vibration, this site has been investigated extensively by means of vibration measurements and numerical simulations [16]. Measurements indicated that the vibrations exceed the threshold levels at night in at least eight buildings [17]. The affected buildings have two to three floors and are mostly built around 1950. The highest vibration levels were measured in the frequency range 4-5 Hz. In November 2011 a sheet pile wall with a length of $100 \mathrm{~m}$ was installed next to the track to mitigate the vibrations [17]. Measurements after installation of the sheet pile wall have shown sufficient reduction of vibration levels, except for one small wooden house at approximately $40 \mathrm{~m}$ from the track. Figure 1 shows the site and the track. The affected buildings are located west of the track. Free field vibration measurements were performed in October 2011 at an orthogonal distance of $8 \mathrm{~m}$, $16 \mathrm{~m}$ and $64 \mathrm{~m}$ from the track (red dots on figure 1(a)); these data are used in this paper for the validation of the computed free field vibrations.

(a)

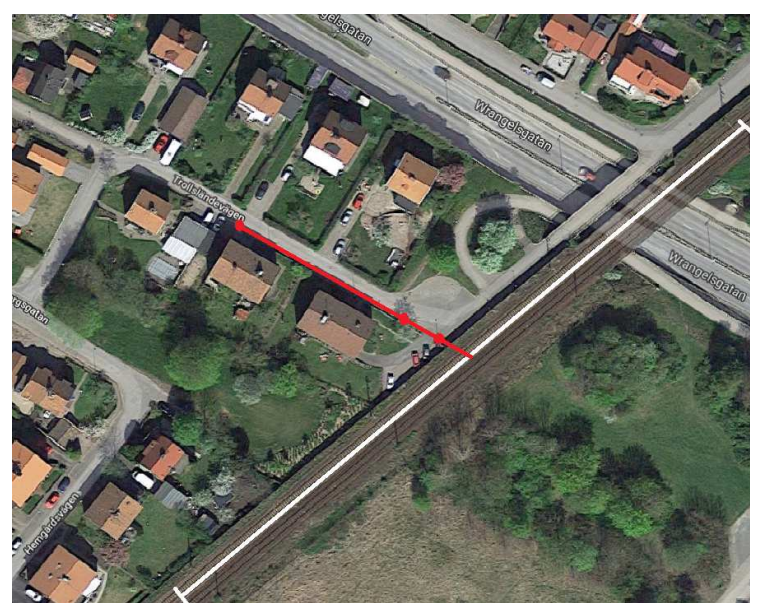

(b)

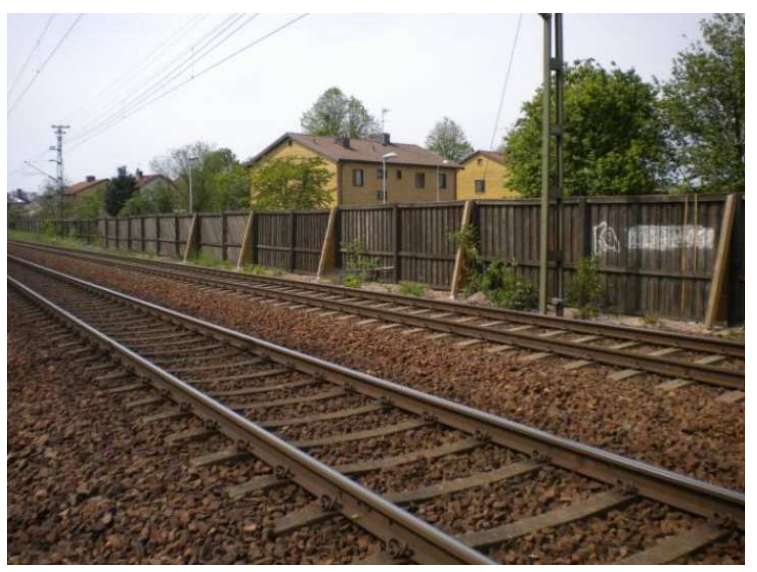

Figure 1: (a) Overview of the site and (b) two ballasted tracks at Furet [16]. The white line indicates the track section modeled with varying stiffness, the red dots indicate the locations of the free field measurements. 
The tracks consist of continuously welded BV50 rails fixed on standard concrete monoblock sleepers, connected by Pandrol Fastclip systems. The sleeper spacing is $0.65 \mathrm{~m}$. The rubber rail pads on the western and eastern tracks have a thickness of $10 \mathrm{~mm}$ and $4 \mathrm{~mm}$, respectively. On the western track, under sleeper pads are placed. The properties of the rails, rail pads, sleepers and under sleeper pads are summarized in table 1 .

The soil characteristics were determined by Cone Penetration Tests (CPTs), Seismic Cone Penetration Tests (SCPTs) and two Spectral Analysis of Surface Waves (SASW) tests. The boreholes revealed the presence of a relatively firm layer of sand up to $2 \mathrm{~m}$ depth, underlain by clayey silt up to $12 \mathrm{~m}$ depth and silty clay underneath. The results of the SCPT and SASW tests were in good agreement [17]. The resulting shear wave velocity $C_{\mathrm{s}}$, longitudinal wave velocity $C_{\mathrm{p}}$, material damping ratios $\beta_{\mathrm{s}}$ and $\beta_{\mathrm{p}}$ in shear and dilatational deformation and density $\rho$ of the ballast and soil are shown in table 2 .

\begin{tabular}{ll}
\hline Rails & $\rho A=50 \mathrm{~kg} / \mathrm{m}$ \\
& $E I=4092 \times 10^{3} \mathrm{Nm}^{2}$ \\
Rail pads (west) & $k_{\mathrm{rp}}=70 \times 10^{6} \mathrm{~N} / \mathrm{m}$ \\
& $c_{\mathrm{rp}}=15 \times 10^{3} \mathrm{Ns} / \mathrm{m}$ \\
& $k_{\mathrm{rp}}=400 \times 10^{6} \mathrm{~N} / \mathrm{m}$ \\
Rail pads (east) & $c_{\mathrm{rp}}=15 \times 10^{3} \mathrm{Ns} / \mathrm{m}$ \\
& $m=298 \mathrm{~kg}$ \\
Sleepers & $l=2.50 \mathrm{~m}$ \\
& $b=0.28 \mathrm{~m}$ \\
Under sleeper pads (west) & $k_{\text {usp }}=45.5 \times 10^{6} \mathrm{~N} / \mathrm{m}$ \\
& $c_{\text {usp }}=22.8 \times 10^{3} \mathrm{Ns} / \mathrm{m}$ \\
& $m_{\text {usp }}=2.45 \mathrm{~kg}$ \\
\hline
\end{tabular}

Table 1: Properties of the track superstructure.

\section{Measured track stiffness and geometry data}

To evaluate the individual contributions of longitudinal track unevenness and track stiffness variation to the train-track interaction forces, measurement data are needed. Most convential track recording cars measure the longitudinal level $u_{\text {axle }}(x)$ as experienced by the axles while running on the track. This deflection is due to both the track unevenness $u_{\mathrm{unev}}(x)$ and the effect of the track stiffness variation $k_{\mathrm{track}}(x)$ :

$$
\begin{aligned}
u_{\text {axle }}(x) & =u_{\text {unev }}(x)+u_{\text {load }}(x) \\
& =u_{\text {unev }}(x)+\frac{W_{\text {axle }}}{k_{\text {track }}(x)}
\end{aligned}
$$




\begin{tabular}{cccccc}
\hline Layer & $\begin{array}{c}h \\
(\mathrm{~m})\end{array}$ & $\begin{array}{c}C_{\mathrm{s}} \\
(\mathrm{m} / \mathrm{s})\end{array}$ & $\begin{array}{c}C_{\mathrm{p}} \\
(\mathrm{m} / \mathrm{s})\end{array}$ & $\begin{array}{c}\beta_{\mathrm{s}}=\beta_{\mathrm{p}} \\
(-)\end{array}$ & $\begin{array}{c}\rho \\
\left(\mathrm{kg} / \mathrm{m}^{3}\right)\end{array}$ \\
\hline Ballast & 0.50 & 150 & 300 & 0.030 & 1800 \\
1 & 2 & 154 & 375 & 0.025 & 1800 \\
2 & 10 & 119 & 290 & 0.025 & 1850 \\
3 & $\infty$ & 200 & 490 & 0.025 & 1710 \\
\hline
\end{tabular}

Table 2: Dynamic ballast and soil characteristics in Furet (Sweden).

The Infranord Measurement Vehicle with maximum speed $100 \mathrm{~km} / \mathrm{h}$ (IMV100, figure 2) allows to make the distinction between these two contributions to the total vertical displacement of the axles. The IMV100 measures longitudinal level using two systems: an inertia based system by means of accelerometers on the car body and compensation Linear Variable Differential Transformers (LVDTs) between the car body and the wheel set, and a mechanical chord system. For the latter, a loaded measurement wheel is placed in the middle of two lightly loaded measurement wheels. The chord level is defined as the vertical distance between the chord connecting the deflections at the lightly loaded wheels and the deflection at the loaded wheel.

The novelty of the EBER Vertical Stiffness (EVS) method [9] consists in combining the inertia and chord based systems in order to differentiate between the unloaded track unevenness and the effect of loading. The method considers the track as a beam on a Winkler foundation, the foundation stiffness is computed from the measured data using a nonlinear Kalman filter.

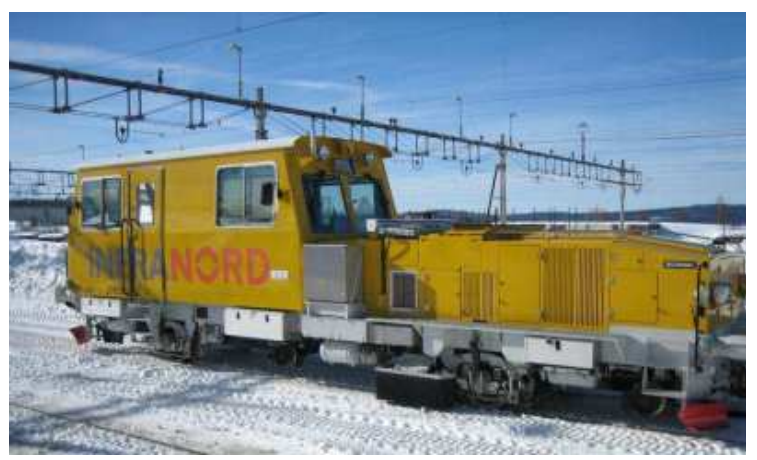

Figure 2: Infranord Measurement Vehicle IMV100 [16].

For a track section of over $2 \mathrm{~km}$, the track stiffness and track unevenness were measured for both tracks with the IMV100 on 4 June 2013. A track section of $200 \mathrm{~m}$ (white line on figure 1(a)) with uniform track characteristics, centered on the line where the free field vibrations were measured (red line on figure 1(a)) is 
selected for the computations. The measured track unevenness and stiffness variation for both the western and eastern track are shown in figures 3 and 4. During the measurement with the IMV100, both rails are loaded simultaneously. Therefore, the track stiffness is defined as the inverse of the vertical rail displacement when a point force of $1 \mathrm{~N}$ is acting on each rail. The average track stiffness and the track stiffness variation are relatively low for the western track due to the presence of the under sleeper pads.

(a)

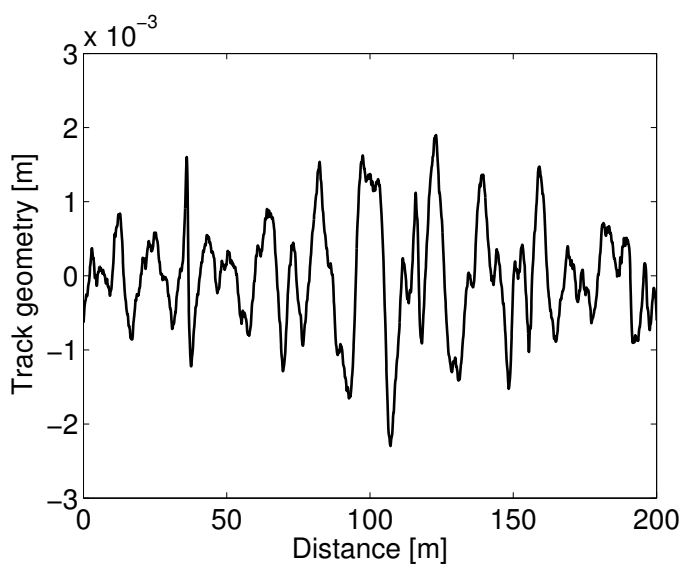

(b)

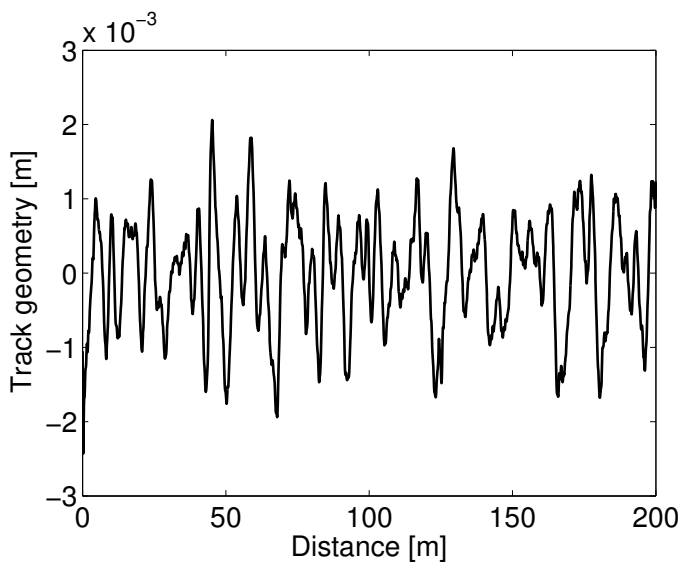

Figure 3: Track unevenness of the (a) western and (b) eastern track at Furet measured by the IMV100.

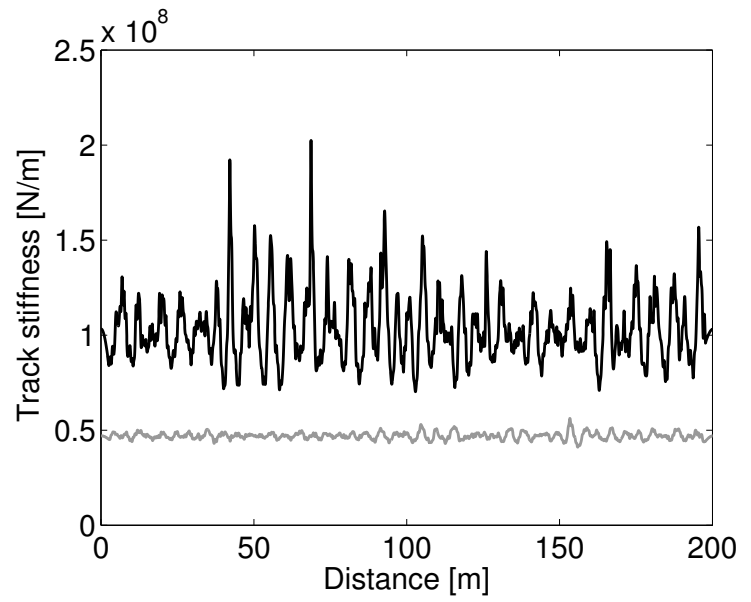

Figure 4: Track stiffness of the western (grey line) and eastern (black line) track at Furet measured by the IMV100.

Figure 5 shows the power spectral density (PSD) function of the track unevenness for the western and eastern track in the wavenumber domain, as well as the vertical rail deflection under a static load of 10 tonnes per axle, computed using the measured track stiffness. An axle load of 10 tonnes is chosen here, as it corresponds to the average load carried by a passenger train axle. This figure also indicates reference curves corresponding to the criteria by Braun and Hellenbroich [18], giving a PSD $G_{\mathrm{uw} / \mathrm{r}}\left(k_{\mathrm{y}}\right)$ based on the statistical properties 
of a large database of unevenness profiles:

$$
G_{\mathrm{uw} / \mathrm{r}}\left(k_{\mathrm{y}}\right)=G_{\mathrm{uw} / \mathrm{r}}\left(k_{\mathrm{y} 0}\right)\left(\frac{k_{\mathrm{y}}}{k_{\mathrm{y} 0}}\right)^{-w},
$$

with $k_{\mathrm{y} 0}=1 \mathrm{rad} / \mathrm{m}$ and $w=3.5$. The parameter $G_{\mathrm{uw} / \mathrm{r}}\left(k_{\mathrm{y} 0}\right)$ defines the track quality. In figure 5 , the curves with $G_{\mathrm{uw} / \mathrm{r}}\left(k_{\mathrm{y} 0}\right)=1 \times 10^{-9} \mathrm{~m}^{3}, 3 \times 10^{-8} \mathrm{~m}^{3}$ and $5 \times 10^{-7} \mathrm{~m}^{3}$ correspond to very good, medium and very bad track quality, respectively. The track geometry of the western track is of medium quality, while the track geometry of the eastern track is of medium to bad quality. The peak at $9.7 \mathrm{rad} / \mathrm{m}(\lambda=0.65 \mathrm{~m})$ corresponds to the sleeper distance and is present in both the stiffness and geometry data. The origin of the peaks at $8.2 \mathrm{rad} / \mathrm{m}(\lambda=0.77 \mathrm{~m})$ and $5.7 \mathrm{rad} / \mathrm{m}(\lambda=1.10 \mathrm{~m})$ for both tracks is unclear. For the western track, the track unevenness is higher than the static track deflection under an axle load of 10 tonnes for all wavenumbers. For the eastern track, these are of the same order of magnitude for wavenumbers above $5 \mathrm{rad} / \mathrm{m}$ (below $\lambda=1.26 \mathrm{~m}$ ).

(a)

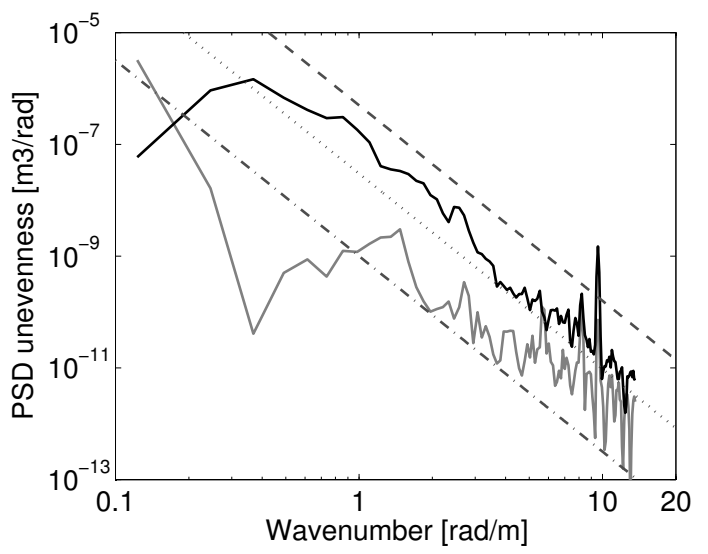

(b)

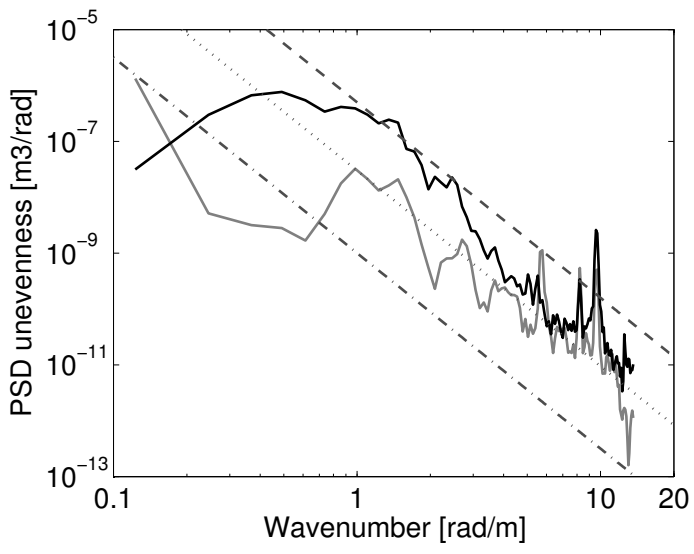

Figure 5: PSD of the track unevenness (black line) and static track deflection for an axle load of 10 tonnes (grey line) of the (a) western and (b) eastern track. PSD of the track unevenness according to the criteria of Braun and Hellenbroich [18] for very good (dashed-dotted line), medium (dotted line) and very bad (dashed line) track quality.

\section{Track models}

In order to compute the contribution of track stiffness variation to the train-track-soil interaction forces, a methodology is used that allows considering the spatial variation of the track properties in the longitudinal direction. The interaction forces and free field vibrations are computed by means of a two-step train-tracksoil coupling algorithm [23]. In the first step, the train-track interaction problem is solved in the time domain to compute the interaction forces. In the second step, these forces are transformed to the frequency domain and used to compute the vibration in the track and free field. An advantage of this two-step coupling algorithm is that it allows using different track models with different levels of detail. 


\subsection{Train-track interaction forces}

For the computation of the interaction forces, a simple track model is used in which the rail pads, under sleeper pads, ballast and soil are modeled by means of masses, springs and dampers (figure 6(a) [19]). The low number of degrees of freedom per sleeper bay in this model allows considering a long section of the track and taking into account the track stiffness variation measured by the IMV100. The ballast and soil properties of the model are tuned in order to fit the measured track stiffness at Furet as good as possible. This is done in two steps.

In the first step, a periodic track model corresponding to figure 6(a) is developed (model A). This model is tuned such that its stiffness closely matches the average track stiffness at Furet, calculated with a periodic finite element-boundary element (FE-BE) model based on the Floquet transform (model B, figure 6(b) [20, 21]). The track subdomain $\tilde{\Omega}_{\mathrm{t}}$ is modeled by finite elements and the soil subdomain $\tilde{\Omega}_{\mathrm{s}}$ by boundary elements. Continuity of displacements and equilibrium of forces are enforced at the interface $\tilde{\Sigma}_{\text {ts }}$. Track model B is built using the known track and soil properties at Furet (tables 1 and 2); its static rail receptance agrees well with the mean track stiffness measured by the IMV100. The rail characteristics, rail pad stiffness $k_{\mathrm{rp}}$ and damping $c_{\mathrm{rp}}$, under sleeper pad stiffness $k_{\mathrm{usp}}$, damping $c_{\mathrm{usp}}$ and mass $m_{\mathrm{usp}}$ and the sleeper properties are the same in models $\mathrm{A}$ and $\mathrm{B}$. The ballast mass $m_{\mathrm{b}}$ in model $\mathrm{A}$ is equally distributed between the masses $M$ and $m_{\mathrm{s}}$ connected by the springs $k_{\mathrm{b}}$. Similarly, the under sleeper pad mass is equally distributed between the masses $m_{\mathrm{sl}}$ and $M$. The ballast damping $c_{\mathrm{b}}$ was determined by assuming structural damping with loss factor 0.03 and calculating an equivalent viscous damping at $6 \mathrm{~Hz}$, the frequency of the first peak in the track receptance due to the soil layering (figure 8 ). The ballast stiffness $k_{\mathrm{b}}$, soil mass $m_{\mathrm{s}}$, vertical and horizontal soil stiffness $k_{\mathrm{Sv}}$ and $k_{\mathrm{sh}}$ and damping $c_{\mathrm{Sv}}$ and $c_{\mathrm{sh}}$ (red elements in figure $7(\mathrm{a})$ ) are tuned separately for the eastern and western track in order to fit the receptance of model A to the receptance of model B between $0 \mathrm{~Hz}$ and $100 \mathrm{~Hz}$.

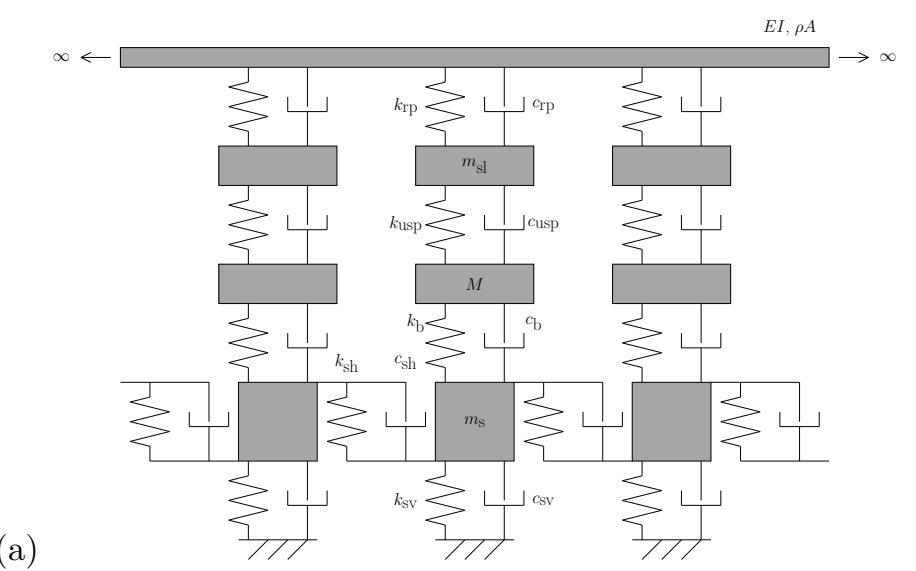

(b)

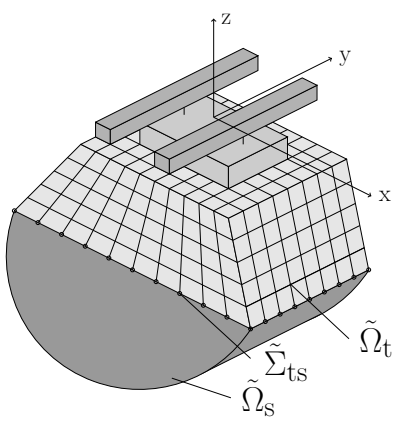

Figure 6: (a) Track model with masses, springs and dampers (model A/C) and (b) periodic FE-BE track model (model B). 


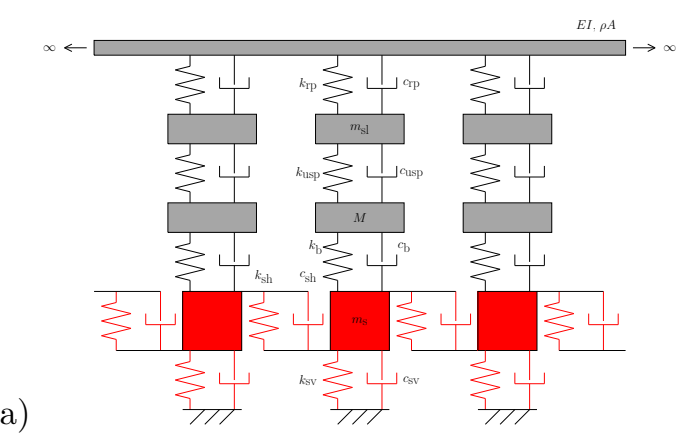

(b)

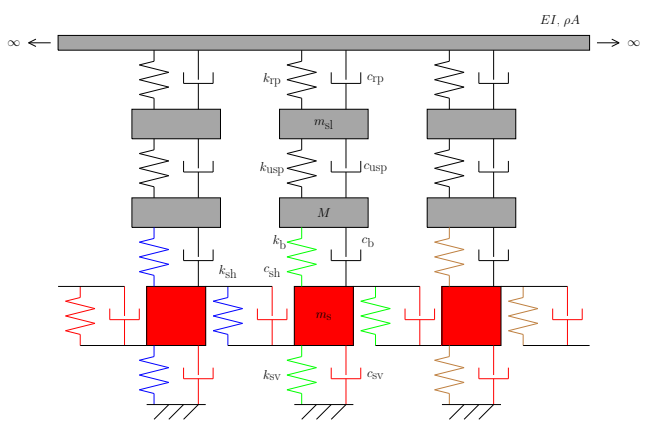

Figure 7: (a) First tuning of the soil properties (red elements) for all cells and (b) second tuning of ballast and soil stiffness (blue, green and brown elements) for each cell separately.

The tuned ballast and soil properties of model A are summarized in table 3 for both tracks. A very good agreement is obtained between the modulus and phase of the receptance of models A and B (figure 8). Analogous to the track stiffness shown in figure 4 , the receptance is defined here as the vertical rail displacement for a point force of $1 \mathrm{~N}$ per rail on top of a sleeper. The western track is clearly less stiff due to the presence of under sleeper pads and softer rail pads. The receptance of both tracks has a peak at $6 \mathrm{~Hz}$ due to the soil stratification, but this peak is only present in the results of model B where the soil layering is taken into account. The peak around $75 \mathrm{~Hz}$ for the western track corresponds to the resonance of the rails and sleepers on the under sleeper pads and is clearly present in both models.

\begin{tabular}{llll}
\hline & & West & East \\
\hline Ballast & $k_{\mathrm{b}}(\mathrm{N} / \mathrm{m})$ & $171.5 \times 10^{6}$ & $172.9 \times 10^{6}$ \\
& $c_{\mathrm{b}}(\mathrm{Ns} / \mathrm{m})$ & $273.0 \times 10^{3}$ & $275.2 \times 10^{3}$ \\
& $M_{\mathrm{b}}(\mathrm{kg})$ & 315 & 315 \\
Soil & $k_{\mathrm{sv}}(\mathrm{N} / \mathrm{m})$ & $24.42 \times 10^{6}$ & $40.04 \times 10^{6}$ \\
& $c_{\mathrm{sv}}(\mathrm{Ns} / \mathrm{m})$ & $433.93 \times 10^{3}$ & $607.87 \times 10^{3}$ \\
& $k_{\mathrm{sh}}(\mathrm{N} / \mathrm{m})$ & $242.80 \times 10^{6}$ & $118.32 \times 10^{6}$ \\
& $c_{\mathrm{sh}}(\mathrm{Ns} / \mathrm{m})$ & $0 \times 10^{3}$ & $0 \times 10^{3}$ \\
& $M_{\mathrm{s}}(\mathrm{kg})$ & 1630 & 1434 \\
\hline
\end{tabular}

Table 3: Ballast and soil properties of model A after tuning for the western and eastern track separately.

In the second step, a non-periodic track model is developed that allows to account for the track stiffness variation (model $\mathrm{C}$ ). This model is a different version of the periodic track model $\mathrm{A}$, with stiffness properties $k_{\mathrm{b}}, k_{\mathrm{sv}}$ and $k_{\mathrm{sh}}$ (blue, green and brown elements in figure $\left.7(\mathrm{~b})\right)$ tuned separately for each sleeper bay in 
(a)

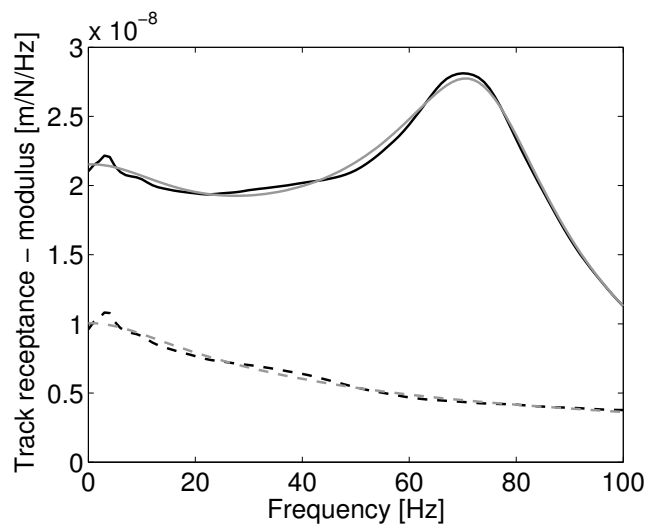

(b)

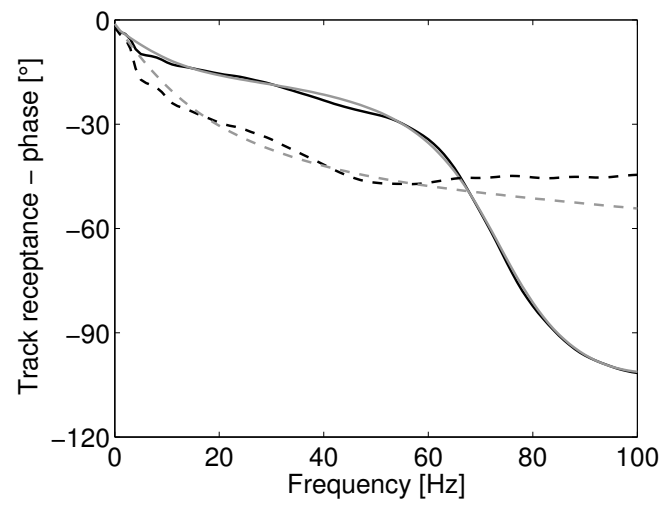

Figure 8: (a) Modulus and (b) phase of the vertical rail receptance of model A (grey line) and model B (black line) for the western (solid line) and eastern (dashed line) track.

order to closely match the stiffness variation measured by the IMV100. The three stiffness parameters of each sleeper bay are multiplied by the same factor to fit the static rail stiffness to the stiffness variation measured by the IMV100. To model the infinite track with varying stiffness, a wave analysis technique for multi-coupled periodic structures as developed by Mead $[22,23]$ is used. The track is modeled as a series of cells, representing the sleeper bays (figure 9). The central part of the track consists of the sleeper bays with varying ballast and soil properties. This central part is connected at both sides to a semi-infinite series of cells (parts 1 and $M$ in figure 9), corresponding to the periodic cell of model A.

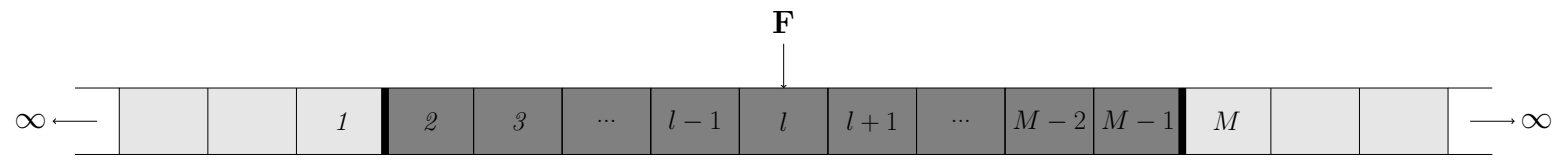

Figure 9: Track structure existing of $M-2$ sleeper bays with varying stiffness characteristics, connected at both sides to a semi-infinite series of sleeper bays with the same stiffness characteristics.

Figures 10 and 11 show the track stiffness measured with the IMV100 and modeled with model C. A very good agreement is obtained for both tracks for wavenumbers up to $5 \mathrm{rad} / \mathrm{m}$. In the spatial domain, the curves overlap almost entirely. For the eastern track, the track stiffness variation is somewhat underestimated for wavenumbers above $5 \mathrm{rad} / \mathrm{m}$. For both tracks, the peak at $8.2 \mathrm{rad} / \mathrm{m}$ is not present in the track stiffness variation of the model. The corresponding wavelength is shorter than two sleeper bays and not represented by the model. The peak at $9.7 \mathrm{rad} / \mathrm{m}$ corresponds to the sleeper spacing and is present in the track model results.

Track model $\mathrm{C}$ is verified by simulating the passage of the IMV100 and comparing the computed and measured wheel deflection. The IMV100 is modeled by a moving mass, equal to half its axle load (6.75 
tonnes). The mass is connected to a massless wheel-rail contact point by a Hertzian spring with linearised spring stiffness $k_{\mathrm{H}}=1 \times 10^{9} \mathrm{~N} / \mathrm{m}$. The track unevenness is disregarded in this computation. Figures 12 and 13 show for both tracks a very good agreement between the measured and computed deflections under the vehicle, with the exception of the peak at $8.2 \mathrm{rad} / \mathrm{m}$. It can be concluded that the stiffness variation of track model $\mathrm{C}$ agrees very well with the measured track stiffness variation in Furet.

(a)

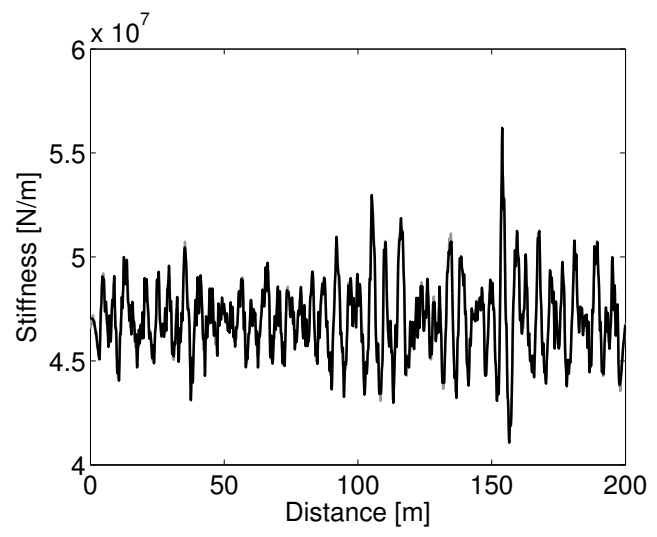

(b)

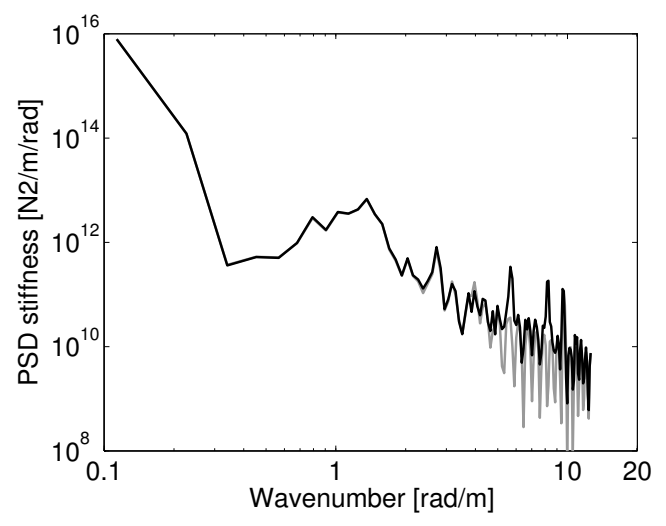

Figure 10: Measured (black line) and modeled (grey line) track stiffness as a function of (a) distance and (b) wavenumber for the western track.

(a)

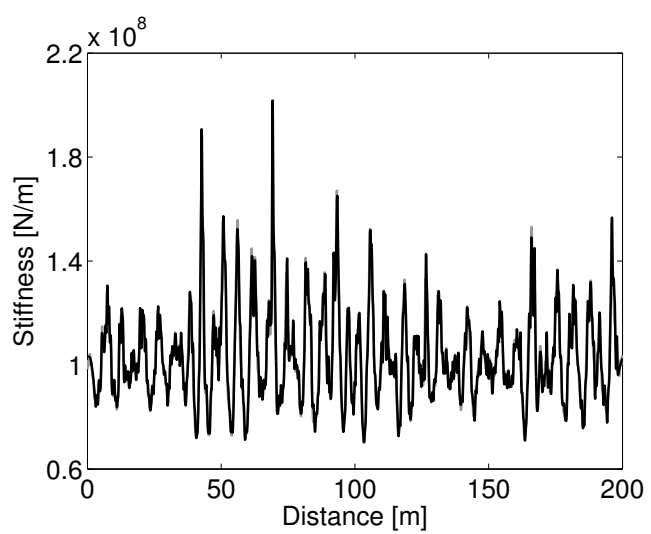

(b)

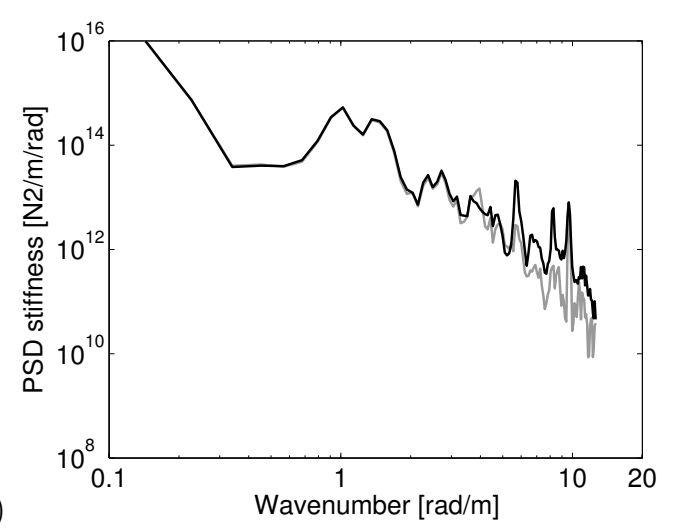

Figure 11: Measured (black line) and modeled (grey line) track stiffness as a function of (a) distance and (b) wavenumber for the eastern track.

\subsection{Free field vibrations}

In the second step of the train-track-soil coupling algorithm, the interaction forces are applied on a more detailed track model that allows computing the vibration transfer to the free field. Ideally, this track model accounts for the changing track characteristics in the longitudinal direction while also allowing to make an 


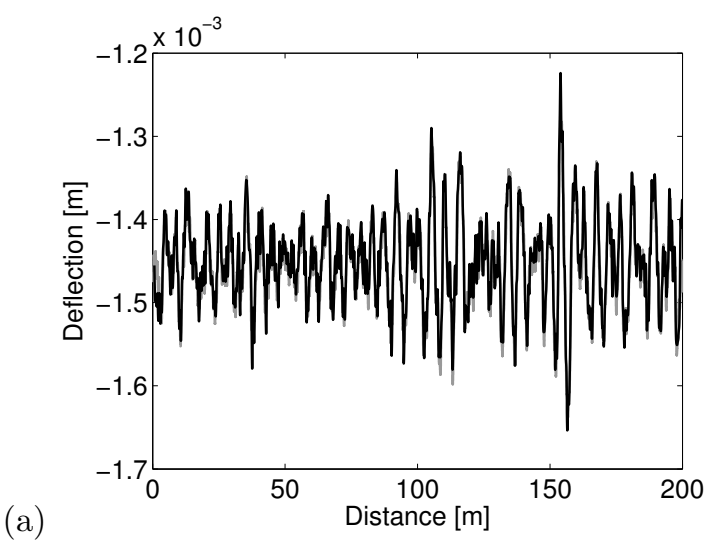

(b)

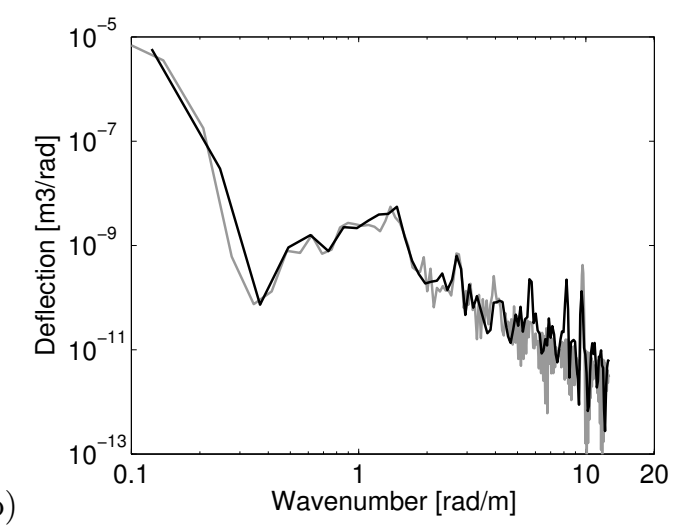

Figure 12: Measured (black line) and computed (grey line) wheel deflection as a function of (a) distance and (b) wavenumber for the western track.

(a)

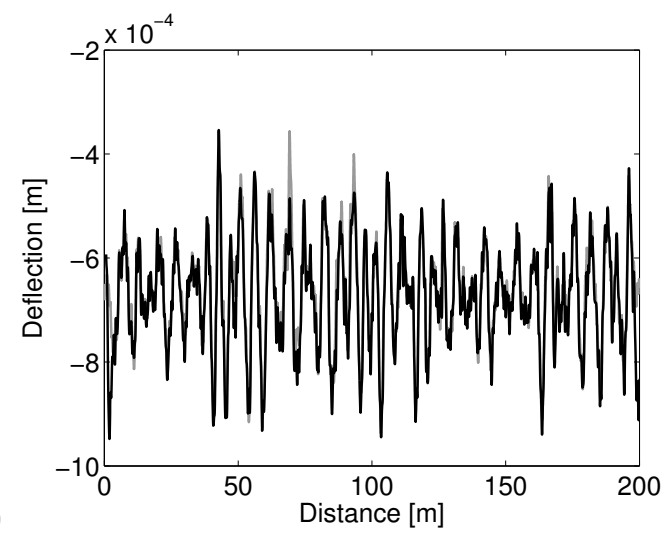

(b)

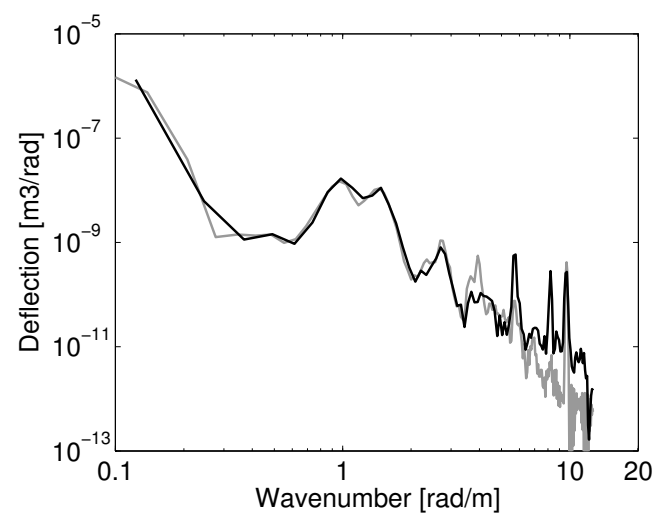

Figure 13: Measured (black line) and computed (grey line) wheel deflection as a function of (a) distance and (b) wavenumber for the eastern track.

accurate prediction of free field vibrations further away from the track. To accomplish this, the track and soil are modeled by a series of cells, each one representing one sleeper bay (figure 14) [23], using finite elements combined with perfectly matched layers (PMLs) $[24,25]$ to prevent wave reflection on the boundaries of the soil domain. In this approach, the stiffness of each sleeper bay can be adjusted in order to match the measured track stiffness variation. The free field vibrations are predicted by computing the displacements at the ballast-soil interface and applying these subsequently on a 2.5D BE model of the soil.

The main obstacle in constructing this track model is attributing the track stiffness variation measured by the IMV100 to a specific track or subgrade component. This variation may be due to variations in rail pad stiffness, ballast or soil conditions, as well as poorly supported sleepers. Also, the computational cost of fitting the model to the measured data and computing the response in the free field would be very high. 


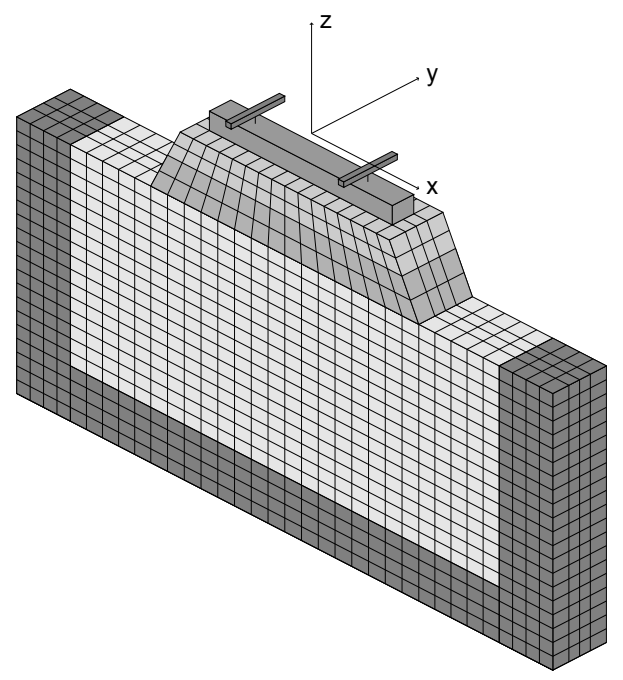

Figure 14: Model of one cell with perfectly matched layers.

Therefore it is assumed that, although the track stiffness variation affects the local track deflection, the effects of softer and stiffer track sections are averaged in the vibration transfer to the free field. To validate this assumption, the effect of track stiffness variation on the computation of the free field vibrations is investigated.

The eastern track in Furet is modeled as a series of cells as shown in figure 14. In the central part, consisting of 11 sleeper bays, the ballast stiffness and sleeper-ballast contact area are varied to obtain a track stiffness variation that has the same order of magnitude as the track stiffness variation measured in Furet. The ballast shear wave velocity varies between $110 \mathrm{~m} / \mathrm{s}$ and $280 \mathrm{~m} / \mathrm{s}$, while the sleeper-ballast contact area varies between a full contact over the entire sleeper length and a $0.45 \mathrm{~m}$ wide contact area underneath each rail. At both sides, this central part of 11 sleeper bays is coupled to a semi-infinite series of cells with ballast and soil properties corresponding to model B (figure 15(a)). The track stiffness in the central 11 sleeper bays is shown in figure $15(\mathrm{~b})$.

The passage of a train on model B is simulated, taking into account the track unevenness measured for the eastern track. The train is modeled as a moving mass of 6.75 tonnes connected to a massless wheel-rail contact point by a Hertzian spring with linearised stiffness $k_{\mathrm{H}}=1 \times 10^{9} \mathrm{~N} / \mathrm{m}$. The resulting interaction forces (figure 16(a)) are applied on 11 consecutive sleepers of two track models: the model with 11 sleeper bays with varying stiffness (figure 15(a)) and the periodic model $\mathrm{B}$. The free field velocity at $8 \mathrm{~m}$ from the track, in the middle of these 11 sleeper bays, is compared for the two track models in figure 16(b). The difference is almost never larger than $1 \mathrm{~dB}$, therefore it is found that the effect of the track stiffness variation on the prediction of the free field vibrations is small. Since it is also very difficult and time consuming to model this track stiffness variation accurately, it is proposed to use model B for the prediction of the free 


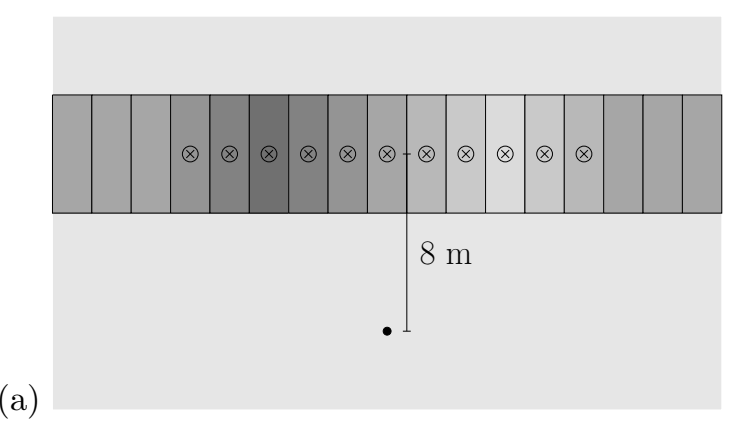

(b)

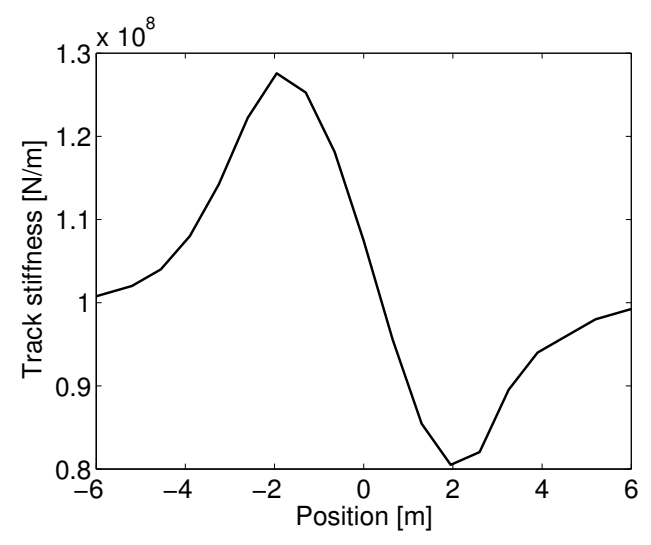

Figure 15: (a) Schematic model of a track with 11 sleeper bays with varying ballast properties and (b) track stiffness variation.

field vibrations.

(a)

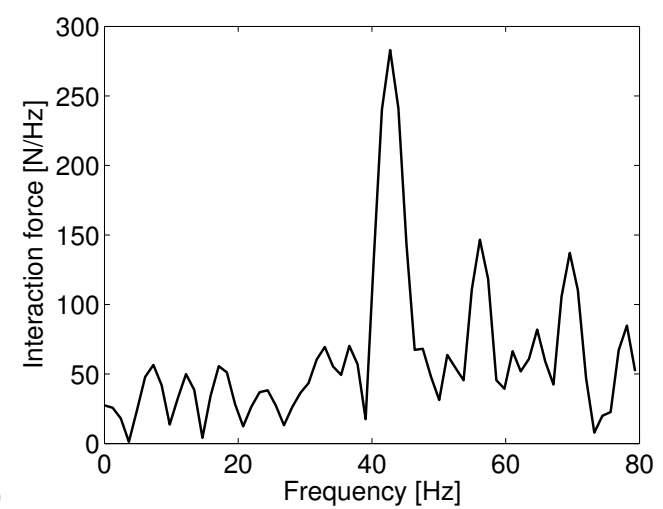

(b)

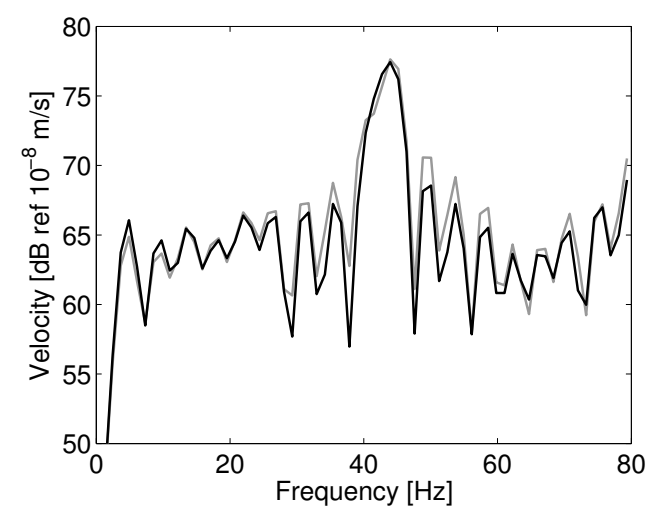

Figure 16: Modulus of the (a) dynamic train-track interaction force and (b) free field velocity at $8 \mathrm{~m}$ from the track center line computed with uniform stiffness (black line) and varying stiffness (grey line).

\section{Results for passenger train passages}

The individual contributions of longitudinal track unevenness and track stiffness variation to the train-track interaction forces and free field vibrations are now studied for the passage of an X31 Öresund passenger train on both tracks in Furet. The interaction forces are computed for three cases. In the first case, only track stiffness variation is considered by computing the train passage on track model $\mathrm{C}$ without taking into account longitudinal track unevenness. In the second case, only track unevenness is considered by computing the train passage on track model A. In the third case, both excitation mechanisms are taken into account by computing the train passage with track unevenness on track model $\mathrm{C}$. 
The X31 Öresund passenger train consists of three cars and has a total length of $78.9 \mathrm{~m}$. The center distance between two bogies within one car is $19 \mathrm{~m}$, the axle distance is $2.7 \mathrm{~m}$. The axles of the first and third cars are driving, those of the middle car are non-driving. Driving and non-driving bogies are modeled with different characteristics. The train speed is $81 \mathrm{~km} / \mathrm{h}$.

The train is modeled by means of six uncoupled bogie models (figure 17), consisting of seven degrees of freedom: the vertical displacements of the car body, bogie, two wheel sets and two wheel-rail contact points and the pitch rotation of the bogie. The car body and bogie have mass $m_{\mathrm{cb}}$ and $m_{\mathrm{b}}$, respectively, and are connected by the secondary suspension, modeled by a spring $k_{\mathrm{s} 2}$ and damper $c_{\mathrm{s} 2}$. The bogie with moment of inertia $I_{\mathrm{b}}$ is connected to the wheel sets with mass $m_{\mathrm{w}}$ by the primary suspension, modeled by a spring $k_{\mathrm{s} 1}$ and damper $c_{\mathrm{s} 1}$. The wheel sets are connected to massless wheel-rail contact points by linearised Hertzian springs $k_{\mathrm{H}}$. As the train and track are assumed to be symmetric and the track model consists of only one rail, the characteristics of the vehicle model correspond to one symmetric half of a bogie and one fourth of the car body. Due to confidentiality reasons, the input data for the bogies are not published in this paper.

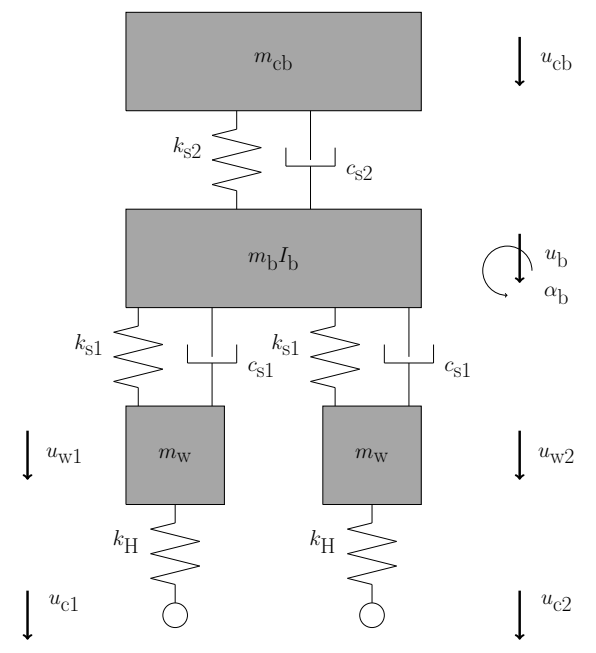

Figure 17: Vehicle model with seven degrees of freedom.

Figure 18 shows the time history and frequency spectrum of the train-track interaction force for the first driving axle on the western track. The results considering both track unevenness and track stiffness variation and those considering track unevenness only overlap almost entirely; the contribution of track stiffness variation is very low for this track. Slightly higher interaction forces are obtained when both excitation mechanisms are taken into account, especially between $5 \mathrm{~Hz}$ and $20 \mathrm{~Hz}$. In the case where only the track stiffness variation is taken into account, parametric excitation due to the periodic rail supports is the main dynamic excitation mechanism. The dynamic train-track interaction force is then very low for all frequencies, except for the sleeper passing frequency at $34.6 \mathrm{~Hz}$. 
Figure 19 shows the time history and frequency spectrum of the train-track interaction force for the first driving axle on the eastern track. The average track stiffness and track unevenness are higher for this track compared to the western track. As a result, the train-track interaction forces are higher for all three considered cases, except between 25 and $40 \mathrm{~Hz}$. The under sleeper pads make the western track softer, resulting in a lower P2 resonance frequency, where the train and the track have a similar receptance. For the western track, this P2 resonance frequency is between 30 and $40 \mathrm{~Hz}$, resulting in higher train-track interaction forces in this frequency range.

The eastern track has a higher track stiffness variation, causing higher interaction forces when only considering this excitation mechanism. Also for the eastern track, however, the contribution of the track stiffness variation to the total interaction force is found to be very low, since the results considering both track unevenness and track stiffness variation and those considering only track unevenness are very similar.

(a)

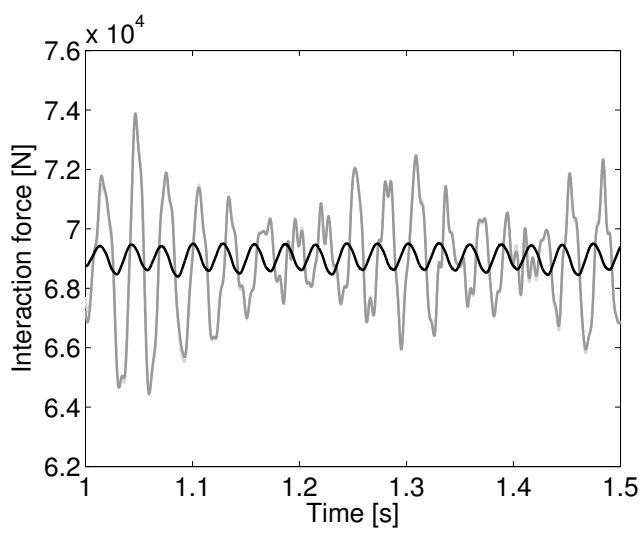

(b)

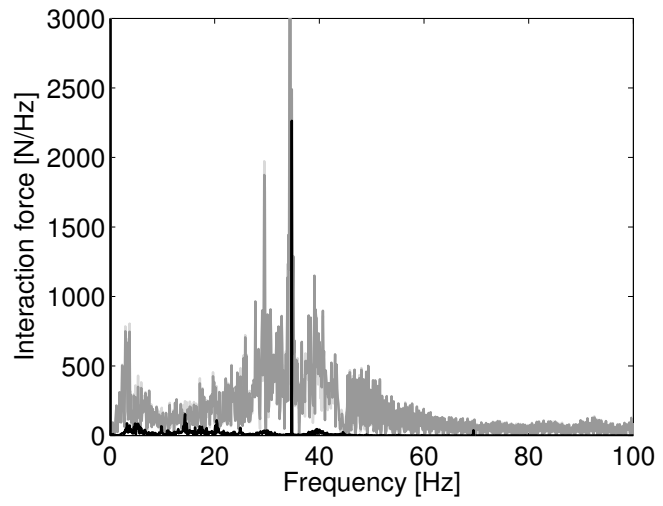

Figure 18: (a) Time history and (b) frequency spectrum of the train-track interaction force for the first driving axle of an X31 Öresund passenger train at $81 \mathrm{~km} / \mathrm{h}$ on the western track, taking into account track stiffness variation (black line), track unevenness (dark grey line) and both excitation mechanisms (light grey line).

The interaction forces computed for the three cases are used to compute the resulting free field vibrations. The computations are verified by a comparison to free field vibrations at $8 \mathrm{~m}, 16 \mathrm{~m}$ and $64 \mathrm{~m}$ from the track center line (red dots on figure 1(a)), measured during the passage of an X31 Öresund passenger train at $81 \mathrm{~km} / \mathrm{h}$ on the western track in October 2011. In this comparison, the results in the center of the modeled track section of $200 \mathrm{~m}$, taking into account both track unevenness and track stiffness variation, are used. The predicted vibrations contain the quasi-static as well as the dynamic component.

Figure 20 shows the time history and 1/3 octave band spectrum of the measured and computed free field velocity at $8 \mathrm{~m}$ from the track center line. The general trends in the $1 / 3$ octave band spectra are very similar. Between $4 \mathrm{~Hz}$ and $20 \mathrm{~Hz}$, the computed results seem to underestimate the measured free field vibrations. Above $20 \mathrm{~Hz}$, the computed results overestimate the measured vibrations. The difference between the 
(a)

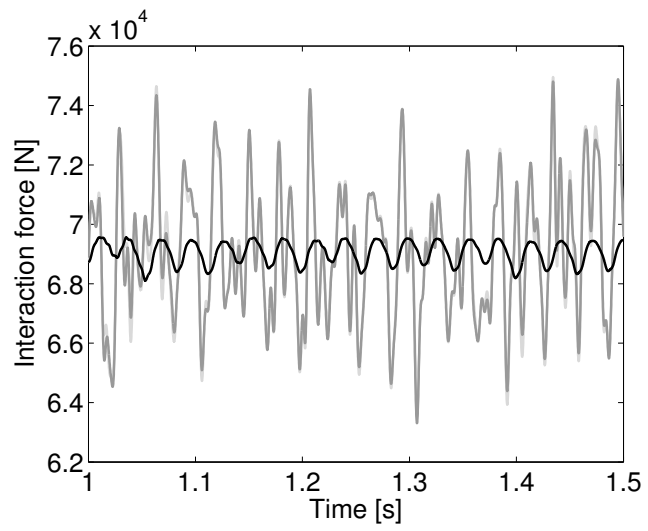

(b)

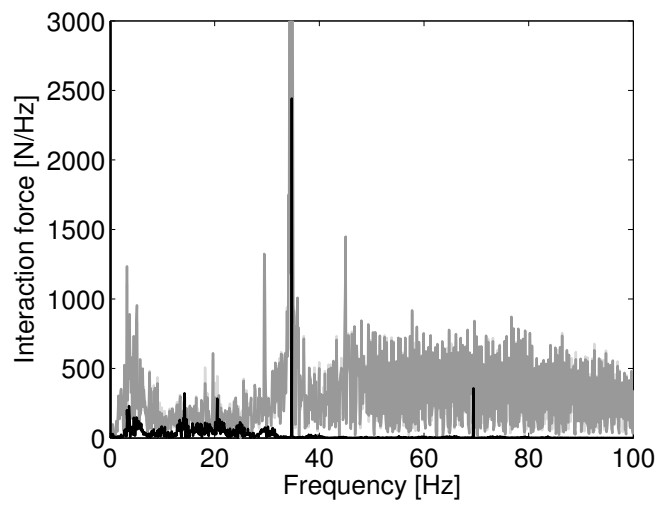

Figure 19: (a) Time history and (b) frequency spectrum of the train-track interaction force for the first driving axle of an X31 Öresund passenger train at $81 \mathrm{~km} / \mathrm{h}$ on the eastern track, taking into account track stiffness variation (black line), track unevenness (dark grey line) and both excitation mechanisms (light grey line).

measured and computed vibrations is below $10 \mathrm{~dB}$ at all frequencies. The peak at $31.5 \mathrm{~Hz}$ corresponds to the sleeper passage frequency.

Figures 21 and 21 show the computed and measured time history and $1 / 3$ octave band spectrum of the free field velocity at $16 \mathrm{~m}$ and $64 \mathrm{~m}$ from the track center line. The computed free field velocities underestimate the vibrations at low frequencies. At $16 \mathrm{~m}$ from the track, the computed results overestimate the measurements above $25 \mathrm{~Hz}$. The difference between the computed and measured vibration is at most $10 \mathrm{~dB}$, except at $8 \mathrm{~Hz}$ for the result at $64 \mathrm{~m}$ from the track. In the following, only the results at $8 \mathrm{~m}$ and $16 \mathrm{~m}$ from the track will be showed.

(a)

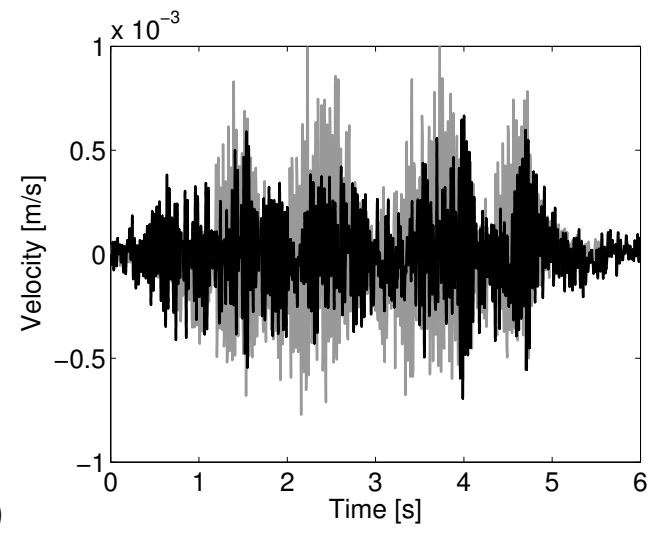

(b)

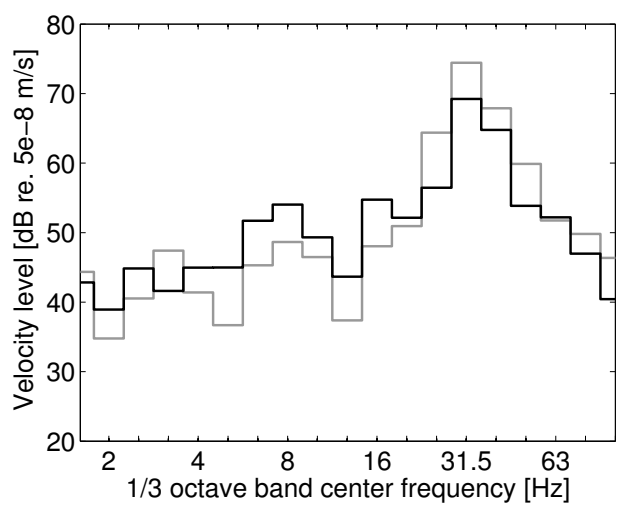

Figure 20: (a) Time history and (b) $1 / 3$ octave band spectrum of the free field velocity at $8 \mathrm{~m}$ from the track center line during the passage of an X31 Öresund passenger train at $81 \mathrm{~km} / \mathrm{h}$ on the western track. Simulated results (grey line) compared to measurement data (black line). 
(a)

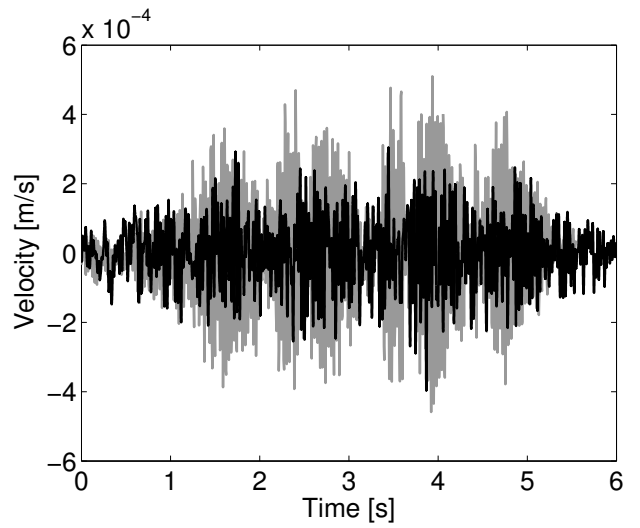

(b)

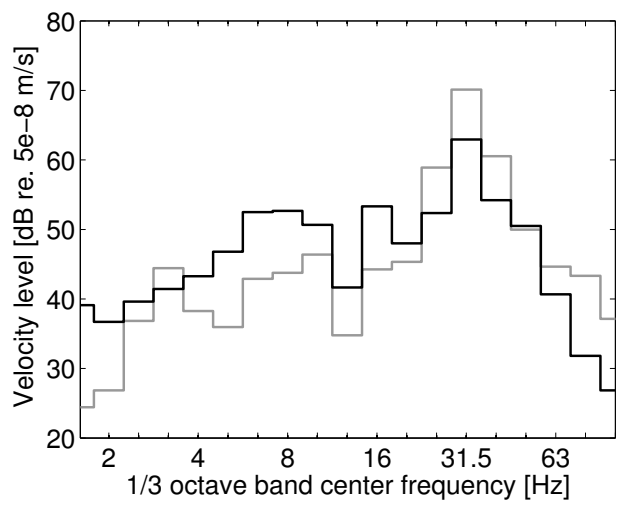

Figure 21: (a) Time history and (b) 1/3 octave band spectrum of the free field velocity at $16 \mathrm{~m}$ from the track center line during the passage of an X31 Öresund passenger train at $81 \mathrm{~km} / \mathrm{h}$ on the western track. Simulated results (grey line) compared to measurement data (black line).

(a)

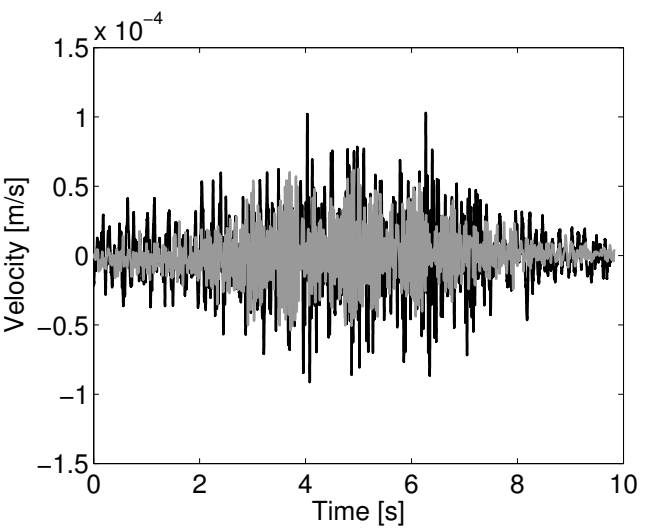

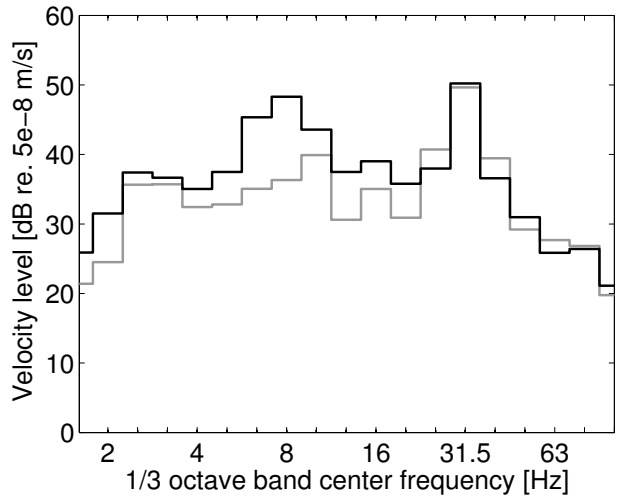

Figure 22: (a) Time history and (b) 1/3 octave band spectrum of the free field velocity at $64 \mathrm{~m}$ from the track center line during the passage of an X31 Öresund passenger train at $81 \mathrm{~km} / \mathrm{h}$ on the western track. Simulated results (grey line) compared to measurement data (black line).

Figure 23 shows the $1 / 3$ octave band spectrum of the free field velocity at $8 \mathrm{~m}$ and $16 \mathrm{~m}$ from the track center line for a train passage on the western track, computed for the three cases. The vibrations when considering only longitudinal track unevenness and those when considering both excitation mechanisms are very similar; the contribution of the track stiffness variation to the total free field vibrations is very small. Figure 24 shows the $1 / 3$ octave band spectrum of the free field velocity at $8 \mathrm{~m}$ and $16 \mathrm{~m}$ from the track center line for a train passage on the eastern track, computed for the three cases. Also for this track, the contribution of the track stiffness variation to the total free field vibrations is very small. The difference between the computed vibrations considering only longitudinal track unevenness and those considering both excitation mechanisms is below $2 \mathrm{~dB}$ between $1 \mathrm{~Hz}$ and $80 \mathrm{~Hz}$ at both receiver points. In agreement with 
figures 18 and 19, the free field vibrations are higher for the eastern track, except between $25 \mathrm{~Hz}$ and $40 \mathrm{~Hz}$.

(a)

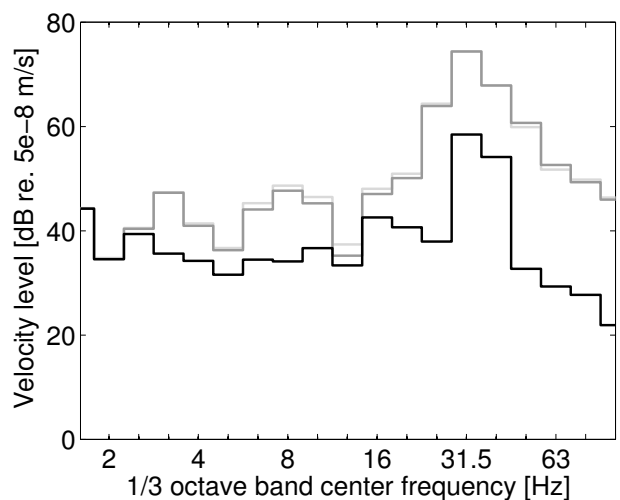

(b)

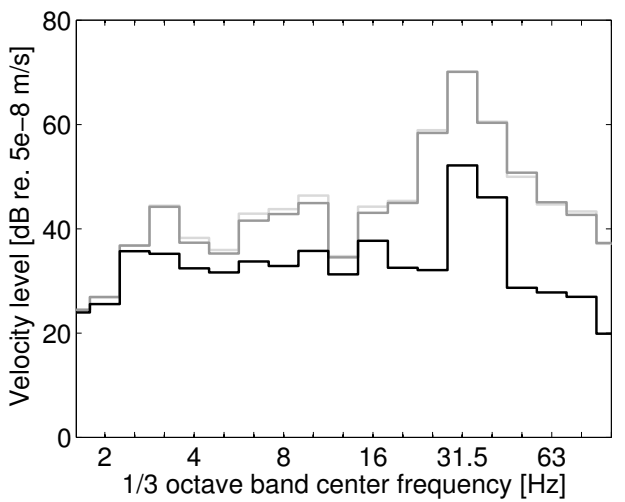

Figure 23: 1/3 octave band spectrum of the free field velocity at (a) $8 \mathrm{~m}$ and (b) $16 \mathrm{~m}$ from the track center line during the passage of an X31 Öresund passenger train at $81 \mathrm{~km} / \mathrm{h}$ on the western track, taking into account track stiffness variation (black line), track unevenness (dark grey line) and both excitation mechanisms (light grey line).

(a)

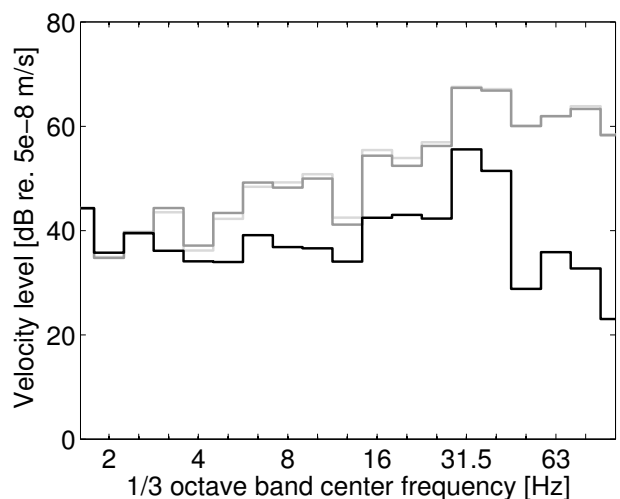

(b)

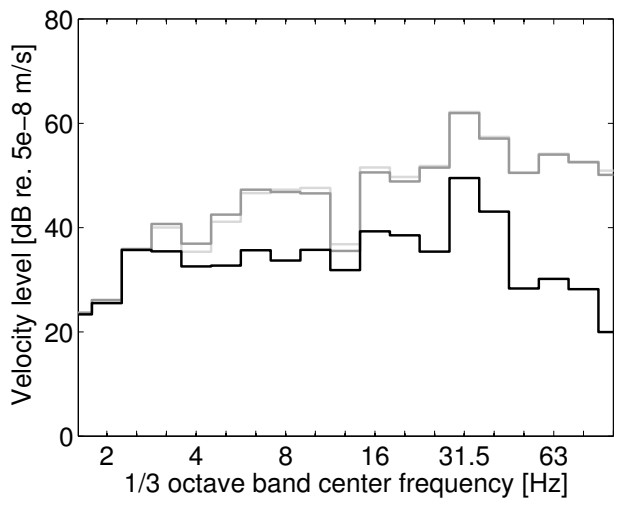

Figure 24: 1/3 octave band spectrum of the free field velocity at (a) $8 \mathrm{~m}$ and (b) $16 \mathrm{~m}$ from the track center line during the passage of an X31 Öresund passenger train at $81 \mathrm{~km} / \mathrm{h}$ on the eastern track, taking into account track stiffness variation (black line), track unevenness (dark grey line) and both excitation mechanisms (light grey line).

In conclusion, it is found that the contribution of track stiffness variation to the train-track interaction forces and free field vibrations is small. Very similar results are obtained when only longitudinal track unevenness is considered. This conclusion holds both for the softer western track with low stiffness variation and for the stiffer eastern track with larger stiffness variation. 


\section{Alternative approach with equivalent track unevenness}

Most railway operators measure the longitudinal track unevenness on a regular basis to monitor the track quality. These measurement data are also commonly used to make predictions of railway induced vibration. Usually, the applied measurement procedure does not allow to distinguish between the longitudinal track unevenness and the deflection due to track stiffness variation. Therefore, most predictions of railway induced vibration are done with a longitudinally invariant or periodic track model, considering an equivalent track unevenness containing both the actual track unevenness and the effect of track stiffness variation.

To investigate the effect of using this equivalent track unevenness, a fourth case is considered. The equivalent track unevenness profile is composed based on the measured track stiffness variation [26]. The deflection data caused by the track stiffness are scaled based on the difference between the weight of an axle of the IMV100 and the X31 Öresund passenger train and then added to the track unevenness. The periodic track model A is used to simulate the train-track interaction. The results obtained with this equivalent unevenness profile are compared to those of the third case in Section 5 where both longitudinal track unevenness and track stiffness variation are considered, the latter by using track model C.

Figure 25 shows the time history and frequency spectrum of the interaction forces for the western track. The results for the eastern track are similar. Using the equivalent track unevenness leads to higher peak interaction forces than modeling the track unevenness and track stiffness variation separately. In the frequency spectrum, higher interaction forces are observed, especially between $15 \mathrm{~Hz}$ and $40 \mathrm{~Hz}$. Between $2 \mathrm{~Hz}$ and $8 \mathrm{~Hz}$, the interaction forces computed with the equivalent unevenness profile are lower.

Figure 26 shows the $1 / 3$ octave band spectrum of the free field velocity at $8 \mathrm{~m}$ and $16 \mathrm{~m}$ from the track center line for a train passage on the western track. It is found that using the equivalent track unevenness leads to slightly different results compared to modeling the track unevenness and track stiffness variation separately. The difference remains below $3 \mathrm{~dB}$ for both the western and eastern track. It is observed that using the equivalent unevenness profile leads to a poorer agreement with measured vibrations.

\section{Conclusions}

In this paper, the individual contributions of longitudinal track unevenness and track stiffness variation to railway induced vibration were studied. In addition, it was studied how track stiffness variation can be modeled as equivalent track unevenness to reduce the modeling effort while only introducing small modeling errors. Measurement data from the Swedish measurement vehicle IMV100 were used to obtain realistic input data. The site at Furet (Sweden) was used as a case study. The free field vibrations due to a passenger train were computed in a two-step procedure.

The dynamic train-track interaction was studied using a vehicle model of the X31 Öresund passenger train and a simple track model. The characteristics of the track model were tuned based on a periodic FE-BE 
(a)

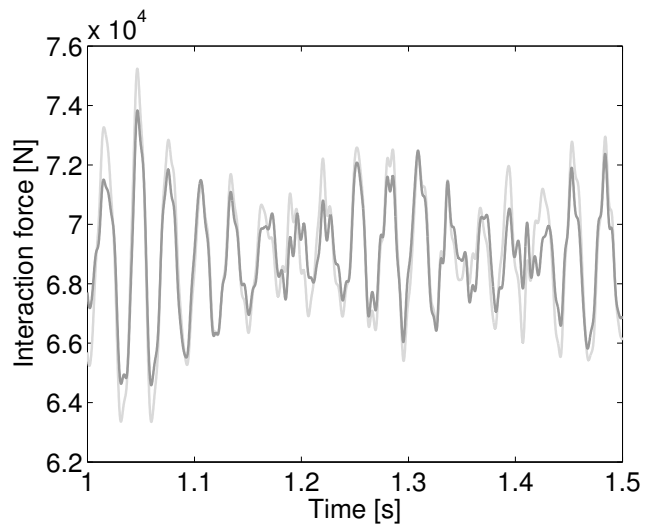

(b)

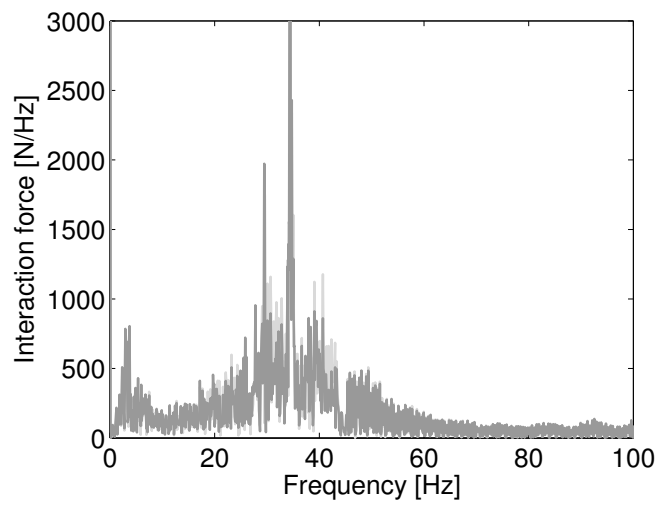

Figure 25: (a) Time history and (b) frequency spectrum of the train-track interaction force for the first driving axle of an X31 Öresund passenger train at $81 \mathrm{~km} / \mathrm{h}$ on the western track, taking into account track stiffness variation and track unevenness separately (dark grey line) or combined in an equivalent track unevenness (light grey line).

(a)

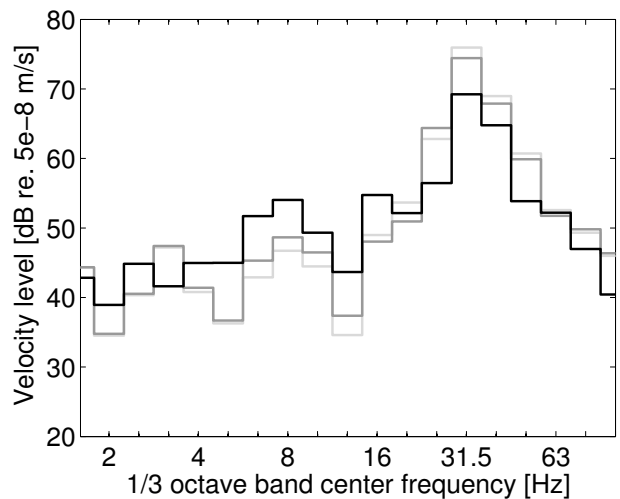

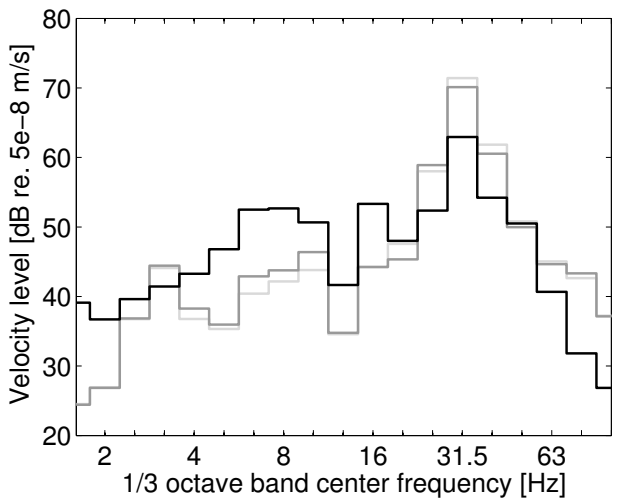

Figure 26: 1/3 octave band spectrum of the free field velocity at (a) $8 \mathrm{~m}$ and (b) $16 \mathrm{~m}$ from the track center line during the passage of an X31 Öresund passenger train at $81 \mathrm{~km} / \mathrm{h}$ on the western track, taking into account track stiffness variation and track unevenness separately (dark grey line) or combined in an equivalent track unevenness (light grey line). The computed vibrations are compared to measured data (black line).

model of the track at Furet and the measured track stiffness variation at this site. The measured stiffness variation is represented very accurately by the track model. The main conclusion from this study is the observation that the interaction forces due to the track stiffness variation are much lower than those due to track unevenness. When both excitation mechanisms are taken into account, the interaction force is slightly higher than when only track unevenness is included.

The free field vibrations were computed by applying the interaction force on the rails of the periodic FE-BE model. The computed results are compared to measured vibrations during the passage of an X31 Öresund passenger train. The agreement between the simulations and measurements is good, with a difference below 
$10 \mathrm{~dB}$ between $1 \mathrm{~Hz}$ and $80 \mathrm{~Hz}$. The contribution of the track stiffness variation to the free field vibration is very small. Very similar results are obtained when only longitudinal track unevenness is taken into account. Between $4 \mathrm{~Hz}$ and $20 \mathrm{~Hz}$, the computed vibrations are slightly higher when both excitation mechanisms are taken into account.

Modeling the track stiffness variation as an equivalent track unevenness leads to slightly different interaction forces and free field vibrations compared to modeling the track unevenness and track stiffness variation separately. The agreement with the measured vibrations is somewhat poorer, but remains reasonably good. It is therefore concluded that an equivalent track unevenness profile can be used for the prediction of railway induced vibration without introducing considerable modeling errors. This is beneficial, since this approach requires much less measurement and modeling effort as well as computation time compared to an approach where track unevenness and track stiffness variation are considered separately.

\section{Acknowledgements}

The first author is a PhD student supported by the Research Foundation Flanders (FWO). The financial support is gratefully acknowledged. The authors thank Dr Eric Berggren from EBER Dynamics for providing the track unevenness and stiffness data from the IMV100 measurement vehicle, and Mr Anders Brandström from Bombardier Transportation for providing the vehicle model input data.

\section{References}

[1] D. Thompson, Railway noise and vibration: mechanisms, modelling, and means of control, Elsevier, Oxford, 2009.

[2] G. Lombaert, G. Degrande, S. François, D. Thompson, Ground-borne vibration due to railway traffic, in: J. Nielsen, D. Anderson, P.-E. Gautier, M. Iida, J. Nelson, D. Thompson, T. Tielkes, D. Towers, P. de Vos (Eds.), Proceedings of the 11th International Workshop on Railway Noise, volume 126 of Notes on Numerical Fluid Mechanics and Multidisciplinary Design, Springer, Heidelberg, New York, Dordrecht, London, Uddevalla, Sweden, 2013, 2013, pp. 253-287. Invited state of the art paper.

[3] M. Heckl, G. Hauck, R. Wettschureck, Structure-borne sound and vibration from rail traffic, Journal of Sound and Vibration 193 (1996) 175-184.

[4] K. Knothe, S. Grassie, Modelling of railway track and vehicle/track interaction at high frequencies, Vehicle System Dynamics 22 (1993) 209-262.

[5] E.G. Berggren, B. S. Paulsson, Track deflection and stiffness measurements from a track recording car, in: Proceedings of the 10th International Heavy Haul Association Conference, New Delhi, India, 2013.

[6] J.C.O. Nielsen, E.G. Berggren, A. Hammar, F. Jansson, R. Bolmsvik, Track geometry degradation on the Swedish heavy haul line - correlation between measured support stiffness gradients and differential settlement, in: Proceedings of the 11th International Heavy Haul Conference, Cape Town, South Africa, 2017, pp. 542-549.

[7] R. Fröhling, Deterioration of railway track due to dynamic vehicle loading and spatially varying track stiffness, Ph.D. thesis, University of Pretoria, Pretoria, South Africa, 1997.

[8] E.G. Berggren, Railway Track Stiffness. Dynamic measurements and evaluation for efficient maintenance, Ph.D. thesis, Royal Institute of Technology (KTH), 2009. 
[9] E.G. Berggren, A. Nissen, B. S. Paulsson, Track deflection and stiffness measurements from a track recording car, Proceedings of the Institution of Mechanical Engineers, Part F: Journal of Rail and Rapid Transit 228 (2014) 570-580.

[10] C. Norman, S. Farritor, R. Arnold, S. Elias, M. Fateh, M. Sibaie, Design of a system to measure track modulus from a moving railcar, in: Proceedings from Railway Engineering, London, United Kingdom, 2004.

[11] Z. Wang, L. Sluys, R. De Borst, Viscoplasticity for instabilities due to strain softening and strain-rate softening, International Journal for Numerical Methods in Engineering 40 (1997) 3839-3864.

[12] L. Andersen, S. Nielsen, Vibrations of a track caused by variation of the foundation stiffness, Probabilistic Engineering Mechanics 18 (2003) 171-184.

[13] J. Oscarsson, Simulation of train-track interaction with stochastic track properties, Vehicle System Dynamics 37 (2002) 449-469.

[14] N. Rhayma, P. Bressolette, P. Breul, M. Fogli, G. Saussine, A probabilistic approach for estimating the behavior of railway tracks, Engineering Structures 33 (2011) 2120-2133.

[15] M.X.D. Li, E.G. Berggren, A study of the effect of global track stiffness and its variations on track performance: Simulation and measurement, Proceedings of the Institution of Mechanical Engineers, Part F: Journal of Rail and Rapid Transit 224 (2010) $375-382$.

[16] J.C.O. Nielsen, E.G. Berggren, T. Lölgen, R. Müller, B. Stallaert, L. Pesqueux, Overview of methods for measurement of track irregularities important for ground-borne vibration, RIVAS project SCP0-GA-2010-265754, Deliverable D2.5, Report to the EC, 2013.

[17] A. Dijckmans, P. Coulier, G. Degrande, G. Lombaert, A. Ekblad, A. Smekal, M. Rodríguez Plaza, Á. Andrés-Alguacil, V. Cuéllar, J. Keil, G. Vukotic, Mitigation measures on the transmission path: results of field tests, RIVAS project SCP0-GA-2010-265754, Deliverable D4.5, Report to the EC, 2013.

[18] H. Braun, T. Hellenbroich, Messergebnisse von Strassenunebenheiten, VDI Berichte 877 (1991) 47-80.

[19] J.C.O. Nielsen, A. Igeland, Vertical dynamic interaction between train and track-influence of wheel and rail imperfections, Journal of Sound and Vibration 187 (1995) 825-839.

[20] D. Clouteau, M. Elhabre, D. Aubry, Periodic BEM and FEM-BEM coupling: application to seismic behaviour of very long structures, Computational Mechanics 25 (2000) 567-577.

[21] G. Degrande, D. Clouteau, R. Othman, M. Arnst, H. Chebli, R. Klein, P. Chatterjee, B. Janssens, A numerical model for ground-borne vibrations from underground railway traffic based on a periodic finite element - boundary element formulation, Journal of Sound and Vibration 293 (2006) 645-666.

[22] D. Mead, The forced vibration of one-dimensional multi-coupled periodic structures: An application to finite element analysis, Journal of Sound and Vibration 319 (2009) 282-304.

[23] M. Germonpré, G. Degrande, G. Lombaert, A track model for railway-induced ground vibration resulting from a transition zone, Proceedings of the Institution of Mechanical Engineers, Part F: Journal of Rail and Rapid Transit (2018).

[24] J. Bérenger, A perfectly matched layer for the absorption of electromagnetic waves, Journal of Computational Physics 41 (1994) 115-135.

[25] S. François, M. Schevenels, G. Lombaert, G. Degrande, A 2.5D displacement based PML for elastodynamic wave propagation, International Journal for Numerical Methods in Engineering 90 (2012) 819-837.

[26] X. Sheng, M. Li, C.J.C. Jones, D.J. Thompson, Using the Fourier-series approach to study interactions between moving wheels and a periodically supported rail, Journal of Sound and Vibration 303 (2007) 873-894. 